\title{
Seismic retrofit for RC columns by NiTi and NiTiNb SMA wires
}

\author{
E. Choi ${ }^{\mathrm{a}, 1}$, K.T. Yang ${ }^{2}$, G.H. Tae ${ }^{3}$, T.H. Nam ${ }^{4}$ and Y.S. Chung ${ }^{5}$ \\ ${ }^{1}$ Hongik University,72-1 Sangsu-dong, Mapo-gu, Seoul 121-791, Korea \\ ${ }^{2}$ Dalim College, 526-7 Bisan-dong Dongan-gu, Anyang, Kyojnggi 431-715, Korea \\ ${ }^{3}$ U-city Solution, 17 Hangdang-dong Seundong-gu, Seoul 133-791, Korea \\ ${ }^{4}$ Gyeoungsang National University,900 Gazaw-dong Jinju, Kyungnam 660-701, Korea \\ ${ }^{5}$ Chungang University, 221 Heuksuk-dong Dongjak-gu, Seoul 156-756, Korea
}

\begin{abstract}
This paper conducted several flexural tests of RC (reinforced concrete) columns retrofitted by SMA (shape memory alloy) wires. The RC columns with lap spliced reinforcements at the base show less ductile behaviour than those with continuous reinforcements. SMA wire jackets can increase the ductility of the RC columns with lap spliced reinforcements and thus this study used the two kinds of SMA wires to retrofit such RC columns; the first one is NiTi SMA wire that remains in martensite at room temperature and the other is NiTiNb SMA wire that is austenite at room temperature. Both the SMA wires show shape memory effect and provide active confinement for concrete. The SMA wires were prestrained to $7 \%$ strain and released. At the state, some residual strain remained and can be recovered by heating. The prestrained SMA wires were wrapped around the plastic hinge region of the RC columns and then the temperature of the wires raised by heating. Then, the SMA wires induced an active confinement on the $\mathrm{RC}$ columns. Each wire was measured for recovery and residual stress to obtain the information of active confinement. This active confinement and the resistance of the SMA wires increased the ductile behaviour of the RC columns in lateral direction. The parameters in this study are the kinds of SMA and the pitch of the wires. All types of the specimens retrofitted the SMA wires showed good ductile behaviour without degrading the flexural strength.
\end{abstract}

\section{INTRODUCTION}

Shape memory alloys (SMAs) can provide confining action to couple two tubes using shape memory effect (SME) [1]. The same confining action can be applied to confine concrete of reinforced concrete structures. Since both applications use shape memory effect of SMAs, it is important to improve the applicability by widening transformation temperature hysteresis. In general, NiTi SMAs have been used to confine concrete of civil structures since they show good mechanical properties, excellent shape memory effect and good corrosion and fatigue resistance [2]. However, the temperature hysteresises of NiTi SMAs are usually not enough for civil structures that are exposed to ambient temperature. For confining concrete by SMAs under ambient temperature, the temperature $\mathrm{M}_{\mathrm{s}}$ where the martensite transformation starts should be less than low ambient temperature (i.e. $10^{\circ} \mathrm{C}$ ) and $\mathrm{A}_{\mathrm{s}}$ where the shape recovery starts be higher than high ambient temperature (i.e. $30^{\circ} \mathrm{C}$ ). Under the condition, the deformed SMAs can be stored at ambient temperature and, after heating beyond the temperature $A_{f}$, the recovery stress of SMAs can remain largely. Thus, large temperature hysteresis between $M_{s}$ and $A_{s}$ is required. However, NiTi alloys show relatively narrow temperature hysteresis and, thus, they are hard to be stored in ambient temperature when $A_{s}$ is relatively low or they remain relatively small recovery stress when $M_{s}$ is relatively high. NiTiNb alloys were introduced and studied to overcome this problem [3-6]. NiTiNb alloys show relatively wide temperature hysteresis and, thus, they can be stored safely and leave relatively large recovery stress at ambient temperature.

Reinforced concrete (RC) columns with lap splice at the base show low ductile behaviour that is not satisfactory during strong earthquakes. External jackets, in general, have been studied to provide additional confinement at the critical section of lap splice and, thus, increased the ductility of RC columns. The conventional materials for external jackets are steel for FRP (Fiber Reinforced Polymer or Plastic). Firstly, steel jackets were considered as external jackets for RC columns with lap splice and showed good performance to increase the flexural strength and the ductility of RC columns. However, they have several drawbacks; steel jackets have the problem of corrosion and grouting and FRP jackets need adhesive to attach themselves and prestressing to confine effectively. Thus, the installation of steel and FRP jackets are not easy. Thus, SMA wire jacket was introduced $[7,8]$.

\footnotetext{
${ }^{a}$ e-mail: eunsoochoiehongik.ac.k
} 
The goal of this study is to verify the excellent performance of SMA wire jackets for lap-spliced RC columns experimentally. For this goal, NiTi and NiTiNb SMA wires were used as external jackets and the recovery and residual stress of them were assessed.

\section{RECOVERY AND RESIDAUL STRESS OF SMA WIRES}

In this study, $47.45 \mathrm{Ni}-37.86 \mathrm{Ti}-14.69 \mathrm{Nb}$ and $53.85 \mathrm{Ni}-46.15 \mathrm{Ti}$ (at \%) SMA wires of $1.0 \mathrm{~mm}$ diameter were used. The both alloys were prepared by high frequency vacuum induction melting, and then hot rolled into wires with a diameter of $1.26 \mathrm{~mm}$ at $850^{\circ} \mathrm{C}$. The hot rolled wires were deformed into a wire with a diameter of $1.0 \mathrm{~mm}$ by cold draw without intermediate annealing. The temperature windows the NiTiNb and the NiTi alloy are shown in Table 1. The transformation hysteresis of the NiTiNb alloy is wider than that of the NiTi alloy. A prestrained martensitic SMA wire with restraining deformation induces recovery stress by heating up above the transition temperature $A_{f}$ but loses some level of the stress by cooling to room temperature as shown in Figure 1; the remaining one is called residual stress. The cause of the lost stress in Figure 1 is that some of austenite transfers to martensite by cooling temperature.

Table 1. Temperature windows of NiTiNb and NiTi alloy

\begin{tabular}{c|c|c|c|c|c}
\hline Alloy & $\mathrm{M}_{\mathrm{s}}\left({ }^{\circ} \mathrm{C}\right)$ & $\mathrm{M}_{\mathrm{f}}\left({ }^{\circ} \mathrm{C}\right)$ & $\mathrm{A}_{\mathrm{s}}\left({ }^{\circ} \mathrm{C}\right)$ & $\mathrm{A}_{\mathrm{f}}\left({ }^{\circ} \mathrm{C}\right)$ & $\mathrm{A}_{\mathrm{s}}-\mathrm{M}_{\mathrm{s}}\left({ }^{\circ} \mathrm{C}\right)$ \\
\hline \hline $\mathrm{NiTiNb}$ & -30.3 & -46.2 & 8.3 & 26.4 & 38.6 \\
\hline $\mathrm{NiTi}$ & 25.0 & 11.1 & 45.1 & 56.0 & 20.1 \\
\hline
\end{tabular}

This study measured the recovery and the residual stresses with varying prestrains of $1-7 \%$. The wires were elongated at $25^{\circ} \mathrm{C}$, heated up to $100^{\circ} \mathrm{C}$ with constraining the deformation and, then, cooled down to $25^{\circ} \mathrm{C}$ again. Figure 2 compares the recovery and the residual stresses of the both wires according to prestrains. For the NiTiNb wire, the maximal recovery and residual stress are $340 \mathrm{MPa}$ and $94 \mathrm{MPa}$, respectively, at the prestrain of 5\%. For the NiTi wire, the both stresses are $223 \mathrm{MPa}$ and $27 \mathrm{MPa}$, respectively, at $5 \%$ prestrain. The test temperature of $25^{\circ} \mathrm{C}$ is just below the $\mathrm{A}_{\mathrm{f}}\left(26.4^{\circ} \mathrm{C}\right)$ of $\mathrm{NiTiNb}$ alloy and, thus, some part of the alloy was austentic phase and others of it was martensitic before elongation. Therefore, the residual stresses are much less than the recovery stresses. For the NiTi alloy, the $25^{\circ} \mathrm{C}$ is just same as the $\mathrm{M}_{\mathrm{s}}\left(25^{\circ} \mathrm{C}\right)$ of the alloy. Thus, during the cooling phase, some part of the alloy became martensitic phase. Thus, the recovery stresses were almost lost and small residual stresses have remained. The maximum residual stress of the NiTiNb alloy at $5 \%$ prestrain was 3.5 times larger than that of the NiTi alloy.

The recovery stresses increase almost linearly up to the maximum stress for the both wires, however, after the maximum point, the stresses decreased a little even with increasing prestrain. The profiles of the residual stresses follow those of the recovery stresses. Elastic deformation and martensite variant rearrangement deformation can be recovered. However, the plastic deformation cannot be recovered. For a relatively large prestrain, it seemed that some plastic deformation was developed and, thus, the residual stress was almost stable after the maximum point. For the NiTi alloy, it seems that the prestrain of 5\% is the limit of martensite variant rearrangement which can be recovered. For the NiTi alloy in this study, when the temperature goes down below $10^{\circ} \mathrm{C}$, it is expected that any residual stress does not remain since $10^{\circ} \mathrm{C}$ is lower than the $\mathrm{M}_{\mathrm{f}}$ of the alloy and the alloy transfers to all martensite. Thus, the NiTi alloy can not be used for confining or prestressing concrete at the temperature lower than $10{ }^{\circ} \mathrm{C}$. However, for the NiTiNb alloy, the $\mathrm{M}_{\mathrm{s}}$ is $-30.3{ }^{\circ} \mathrm{C}$ and, thus, it can show the residual stress even at cold weather of winter.

\section{RETROFIT OF RC COLUMNS BY SMA WIRE JACKETS}

\subsection{Specimens of RC columns}

Five circular columns, each $400 \mathrm{~mm}$ in diameter and $1400 \mathrm{~mm}$ in height, were fabricated with a ratio 3.5, as shown in Figure 3; they were designed following the pre-1992 design code of KHBDS (Korea Highway Bridge Design Specification). Each column was fabricated with 16 D13 longitudinal bars and D6 bars were used for the transverse reinforcement. The measured yield strength of the longitudinal reinforcements was $325 \mathrm{MPa}$. The cover concrete of the specimens was $40 \mathrm{~mm}$ and the center-to-center distance of the longitudinal bars was 67 $\mathrm{mm}$. The maximum aggregate size was $9 \mathrm{~mm}$ and the design compressive strength was $24 \mathrm{MPa}$. Four of the five circular columns had a 50\% lap splice of the longitudinal reinforcements from starter bars projecting from the foundation. Among the 16 bars, half of them were spliced from the starter bars; this means a $50 \%$ lap splice of 
the reinforcements. The length of the lap splice was $200 \mathrm{~mm}$. The remaining column was constructed without the lap slice to compare the results with those of the others.

The used SMA wires were prestrained to $7 \%$ strain at $-50{ }^{\circ} \mathrm{C}$ temperature during the manufacturing process. The wrapping height was $400 \mathrm{~mm}$ that is same as the diameter of the columns. The center-to-center pitches of the wrapping wires were 1.0 and $2.0 \mathrm{~mm}$. Thus, there were two specimens for NiTi and NiTiNb SMA wire, respectively. The first step of the jacketing process was to implant two ahchors into a column at the up and low location to fix the wrapping wire. The second step was to wind the prestrained wires manually around a column and fix it to the ahchors. The third step was to heat the wrapped wires by a heating jacket with the temperature of $200^{\circ} \mathrm{C}$ for 20 minutes and, then, cool down to room temperature. During the above process, the recovery stress of the SMA wires was developed and the residual stress remained to attach the wires tightly around a column. The jacketing process is shown in Figure 4.

Since the test columns were cantilevers, the test set-up was established for a combination of axial and lateral loadings using column-footing assemblages as shown in Figure 5(a). A constant axial load was applied to simulate the dead load of a superstructure. The lateral load was applied at the top of a column. Cyclic lateral loads were applied by a $2000 \mathrm{kN}$ hydraulic actuator mounted on the shear wall. All columns were instrumented to measure displacements and their corresponding loads. The loads and displacements were measured using: (a) the calibrated load cell and displacement transducer of the actuator and (b) displacement transducers installed on the reference frame. Quasi-static load was applied at the top of the columns under displacement control. Lateral load was applied in the form of a drift ratio starting from $\pm 0.25 \%$ that was first increased to $\pm 0.5 \%$, and which was then increased by $0.5 \%$ increments up to failure. The loading history is shown in Figure $5(\mathrm{~b})$.

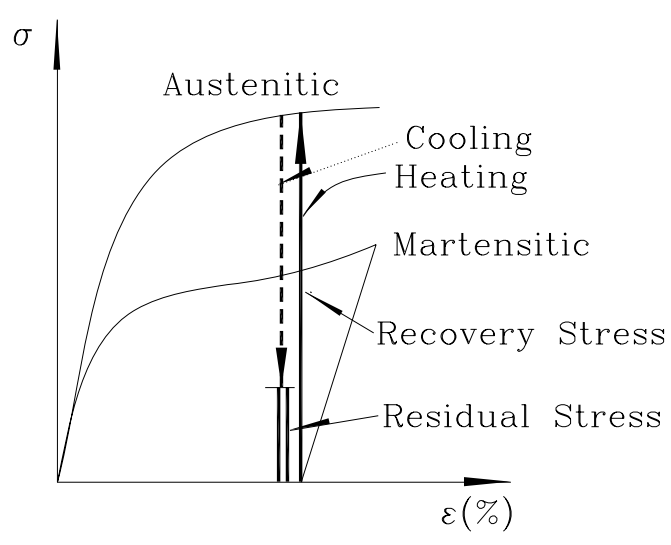

Fig. 1. Schematic diagram of recovery and residual stress

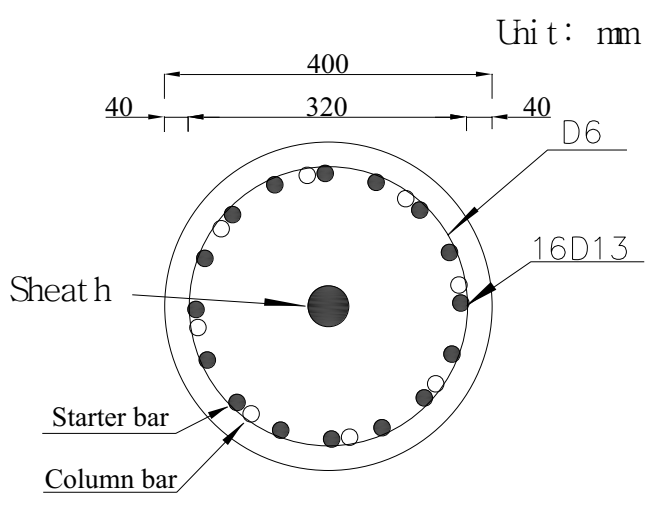

(a) Cross-section

Fig. 3. Details of a specimen

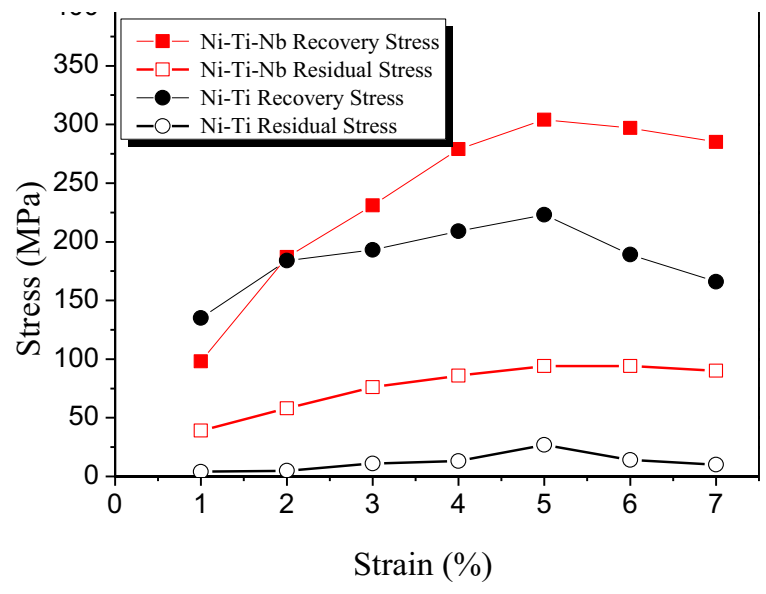

Fig. 2. Recovery and residual stress vs prestrain.

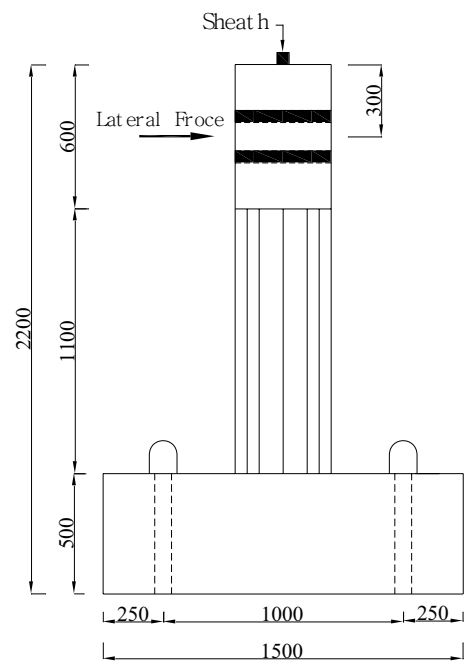

(b) General view 




(a) Wrapping wires

Fig. 4. Jacketing process

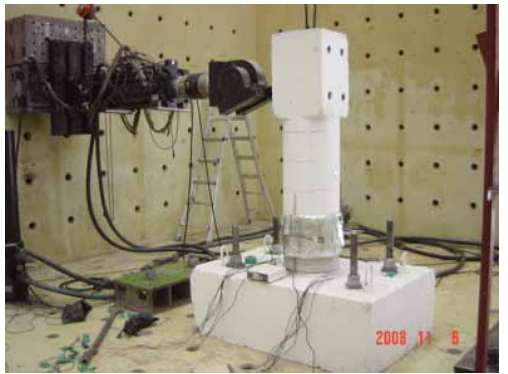

(a) Test set-up

Fig. 5. Test set-up and loading history

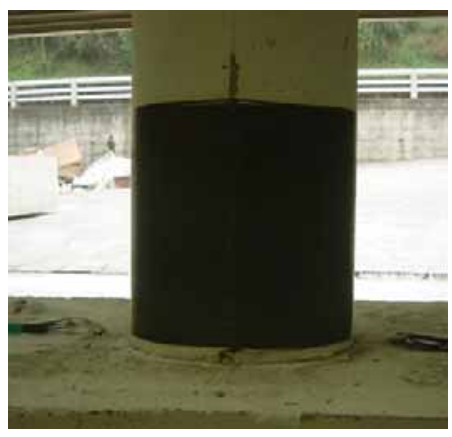

(b) Completed

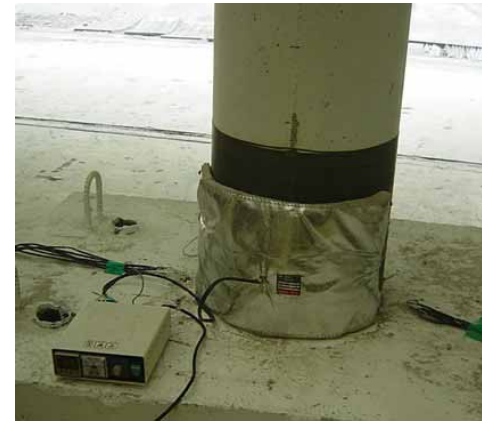

(c) Heating jacket and controller

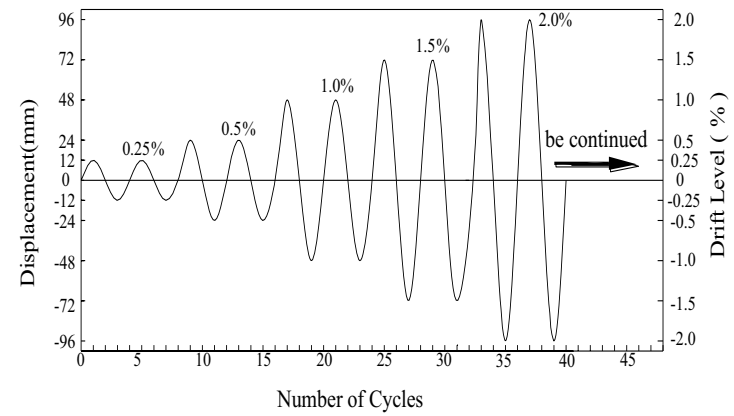

(b) Loading history

\subsection{Discussion of results}

The force-displacement curves of the specimens are shown in Figure 6. In the figure, the lap-spliced and continuous reinforcement are represented by SP50 and SP00, respectively. NT and NTN means the NiTi and $\mathrm{NiTiNb}$, respectivley. The last number represents the pitch of the wrapped wires. Figure 7 shows the envelopes of the hysteretic curves in Figure 6. Table 2 shows the experimental results of ultimate force and failure displacement ; in the table, the (-) means the responses from pulling action.

The RC column with lap-splice showed less ultimate force and failure displacement by $22.6 \%$ and $143 \%$, respectively, than those of the specimen with continous reinforcement. The SMA wire jackets recovered the lack of ultimate force of the lap-spliced specimens up to that of the continuous specimen. Also, they increased the failure displacement of the lap-spliced specimens much more. The mean failure displacement of the jacketed specimens was 6.745 that is 3.49 and 1.44 times of the values of the unjakceted specimens. The NiTiNb SMA wire showed the residual stress of $90 \mathrm{MPa}$ at $7 \%$ prestrain that is 9 times of that of the NiTi SMA wire. However, the relastively large resdiaul stress did not improve the performance of the lap-spliced specimens. It seems that the residual stress was too small to work as active confinement on concrete and just acted to wind the wires tightly. The $1 \mathrm{~mm}$ pitch has 2 times volumetric ratio of the $2 \mathrm{~mm}$ pitch. However, the envelops of the jacketed specimens in Figure 7(b) show similar trends. The $1 \mathrm{~mm}$ pitch wrapping provided more active confinement than the $2 \mathrm{~mm}$ pitch wrapping did. However, the amount of the SMA wires seemed not to influence the behavior of the specimens. It seems that the active confinement of the $1 \mathrm{~mm}$ pitch was too small to improve the responses more. It is conclued from the above observations that even small active confinement provided from the SMA wire jackets can improve the ductile behavior of the lap-spliced RC columns without degrading flexural strength.

Table 2. Experimental results

\begin{tabular}{c|c|c|c|c|c|c}
\hline Response & SP50 & SP00 & SP50-NTN-1 & SP50-NTN-2 & SP50-NT-1 & SP50-NT-2 \\
\hline \hline Ultimate force & 107.8 & 132.2 & 131.5 & 129.0 & 117.0 & 129.5 \\
$(\mathrm{kN})$ & -89.3 & -109.8 & -98.5 & -97.8 & -118.3 & -101.0 \\
\hline Failure displacement & 27.0 & 65.6 & 93.4 & 101.0 & 99.5 & -83.9 \\
$(\mathrm{~mm})$ & -23.0 & -61.9 & -75.5 & -87.5 & -89.7 & -57.9 \\
\hline Drift ratio & 1.93 & 4.69 & 6.67 & 7.21 & -11 & -6.41 \\
$(\%)$ & -1.64 & -4.42 & -5.39 & -6.25 & -4.13 \\
\hline
\end{tabular}



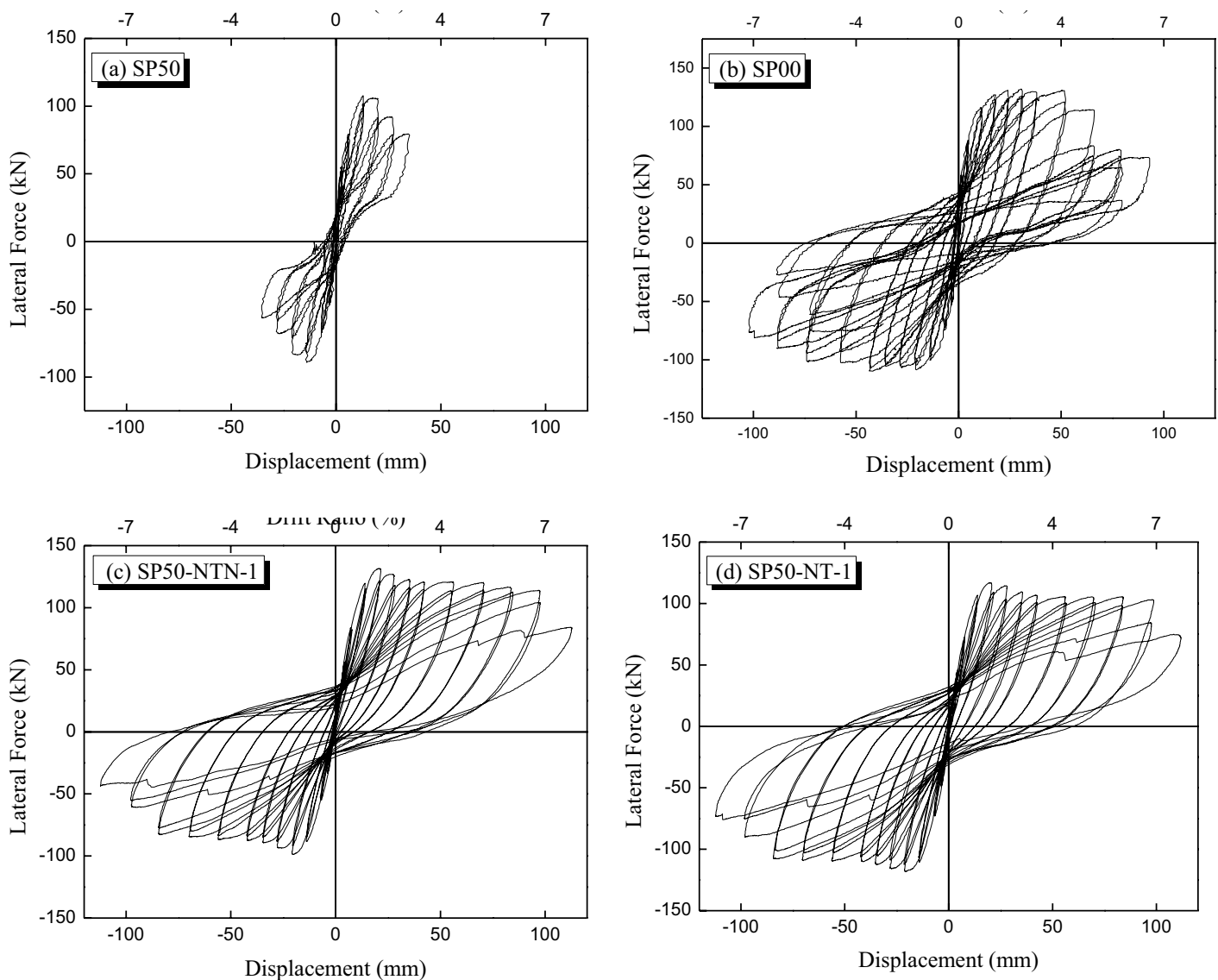

Fig. 6. Force-displacement curves of specimens
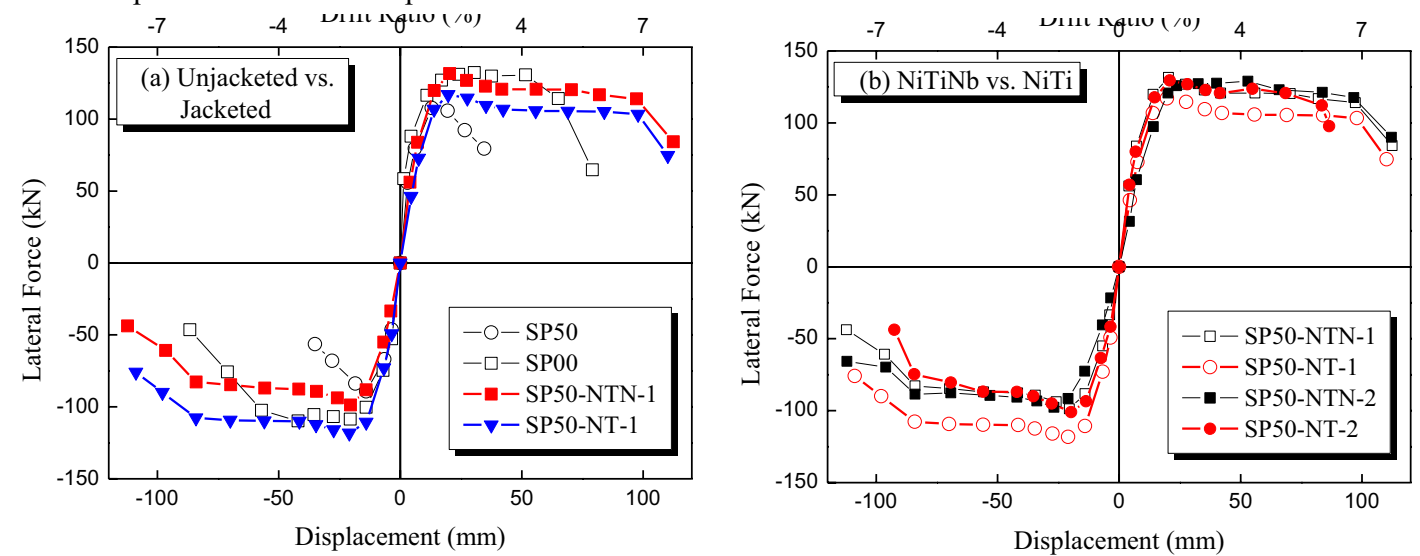

Fig. 7. Envlopes of force-displacement curves

In Figure 7, the SMA wire jakcets did not increase the flexural stiffness of the specemen; the increased stiffness is a negative effect of retrofit of RC columns. The increased stiffness of the columns can draw more seismic acceleration into the columns and, thus, may reduce the effectiveness of external jackets [9].

Figure 8 shows the failure modes of the three specimens. The failure of the lap-spliced specimen occured due to bonding failure at the lap-spliced region. Thus, it showed less ductile behavior as shown in Figure 6(a). The failure of the specimen with continuous reinforcement was firstly initiated from the cracks of cover-concrete and spalling of the cracked cover. Then, the longitudinal reinforcements were buckled due to compression from bending and the core concrete inside longitudianl reinforcements was crushed by compression ; this induced the failure of the specimen. However, for the jacketed specimens, the cracked coverconcrete was not spalled off by the action of the SMA wire jackets. Thus, the cracked cover-concrete protected the longitudinal reinforcements from buckling and reduced the compressive force of the core concrete by sharing the compressive force. This mechanism increased the ductile behavior much more without degrading flexural strength. 


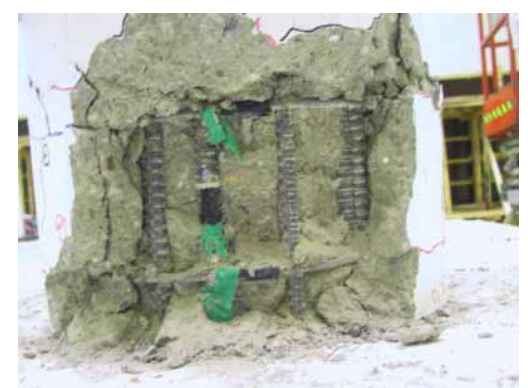

(a) Lap-spliced

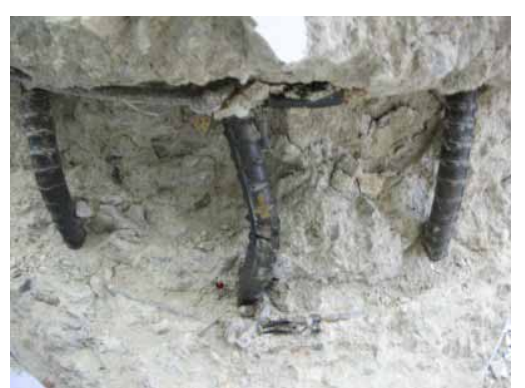

(b) Continuous

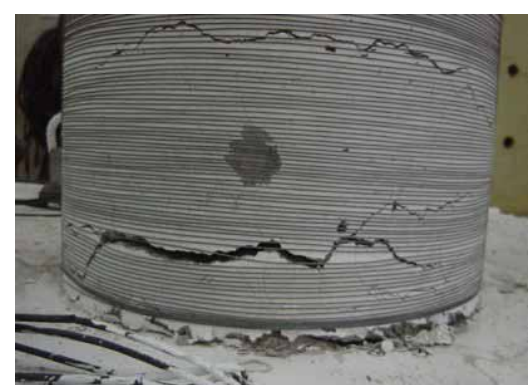

(c) Lap-spliced and jacketed

Fig. 8. Failure modes for the three specimens

\section{CONCLUSIONS}

This study improved the potential of SMA wire jackets experimentally for retrofit of RC columns with lap splice. Also, this study used the NiTiNb SMA wire that is prefered for civil structures considering temperature variation. The NiTiNb SMA wire showed wider temperature hyteresis than the NiTi SMA wire did. Also, ther residual stress of the NiTiNb wire was much higher than the NiTi wire at room temperature.

The performnace of the SMA wire jackets was excellent comparing to the continuous reinforcements RC column. They were not effective to increase the flexural strength but much effective to improve ductile behavior of the RC columns with lap splice. Also, they did not increase the flexural stiffness of jacketed RC columns, which is much desirable for seismic retrofit. Thus, the overall performance of the SMA wire jackets is statisfactory. For the SMA wire jackets, the residual stress and the amount of SMA wire seemed not to influence significantly to improve the ductile behaivor of the RC column with lap splice.

The SMA wire jakcets can be installed manually and tighten by heating. Thus, the installation of the jackets is much easier than the conventional jackets of steel or FRP and the cost of installation may be lower than the other two jackets. Therefore, SMA wire jackets seem to have combativeness although the price of SMAs is high.

\section{Acknowledgment}

This study has been supported by the KOSEF (Korea Science and Engineering Foundation; Project No. R0120060001004802006). The authors would like to thank the financial support.

\section{References}

[1] A.K. Maji, I. Negret, J. Engineering Mechanics 124, 1121 (1998)

[2] R. DesRoches, J. McCormick, M. Delemont, J. Structural Engineering 130 (2004)

[3] C.S. Zhang, L.C. Zhao, Scripta MET. \& MAT 24, 1807 (1990)

[4] M. Kusagawa, T. Nakamura, Y. Asada, JSME, Int. J. Series A, 44, 57 (2001)

[5] W. Seigert, K. Neuking, M. Mertmann, G. Eggeler, J. Phys. IV France, 112, 739 (2003)

[6] X.L. Lu, W. Cai, L.C. Zhao, J. Mat. Sci. Let., 22, 1243 (2003)

[7] B. Andrawes, M. Shin, "Active and Passive Smart Structures and Integrated Systems", Proc.of SPIE, 6928

[8] E. Choi, T.H. Nam, S.C. Cho, Y.S. Chung, T. Park, Smart Materials \& Structures 17, 1 (2008)

[9] Y.H. Chai, M.N.J. Preisetly, J. Structural Engineering, 120, 2358 (1994) 